\title{
Poétiques de la vengeance, De la passion à l'action, éds. Céline Bohnert et Régine Borderie
}

\section{Lise Sabourin}

\section{(2) OpenEdition}

1 Journals

\section{Édition électronique}

URL : http://journals.openedition.org/studifrancesi/4383

DOI : 10.4000/studifrancesi.4383

ISSN : 2421-5856

Éditeur

Rosenberg \& Sellier

\section{Édition imprimée}

Date de publication : 1 septembre 2016

Pagination : 333

ISSN : 0039-2944

\section{Référence électronique}

Lise Sabourin, «Poétiques de la vengeance, De la passion à l'action, éds. Céline Bohnert et Régine Borderie », Studi Francesi [En ligne], 179 (LX | II) | 2016, mis en ligne le 01 septembre 2016, consulté le 18 septembre 2020. URL : http://journals.openedition.org/studifrancesi/4383 ; DOI : https://doi.org/ 10.4000/studifrancesi.4383

Ce document a été généré automatiquement le 18 septembre 2020.

\section{(c)}

Studi Francesi è distribuita con Licenza Creative Commons Attribuzione - Non commerciale - Non opere derivate 4.0 Internazionale. 


\title{
Poétiques de la vengeance, De la passion à l'action, éds. Céline Bohnert et Régine Borderie
}

\author{
Lise Sabourin
}

\section{RÉFÉRENCE}

Poétiques de la vengeance, De la passion à l'action, sous la direction de Céline BOHNERT et Régine BORDERIE, Paris, Classiques Garnier, 2013, 255 pp.

1 Ce volume sur la vengeance, introduit par Régine BORDERIE (pp. 9-27) et postfacé par Céline BONHERT (pp. 217-236), comporte quatre communications portant sur le premier XIX siècle.

2 Roxane MARTIN étudie le traitement de la vengeance dans le mélodrame de René-Charles Guilbert de Pixerécourt (pp. 79-92): elle montre le renversement de tendance entre ses pièces de 1795 à 1814, les plus connues, où la vengeance est présentée comme symptôme de déséquilibre social et de traîtrise punie par la justice, et celles de la Restauration, où elle devient remède vertueux contre des institutions judiciaires perçues comme plus incertaines. Dans les deux cas, Pixerécourt, qui a conçu l'utilité de son théâtre comme liée à l'exorcisme des violences révolutionnaires pour refonder la société sur des valeurs morales et religieuses, présente la vengeance comme un symptôme passionnel réagissant à l'absurdité et cherche à retrouver la sublimation de l'ordre naturel divin, garant de la lutte contre le mal.

3 Olivier BARA, prenant pour corpus La Juive (1835), Le Trouvère (1853), Le Roi d'Ys (1888) et Turandot (joué en 1926), discerne les enjeux des voies / voix de la vengeance à l'opéra au XIX $X^{e}$ siècle (pp.93-107): qu'elle s'inscrive dans un espace temporel historicisé ou légendaire, la vengeance se révèle une matrice féconde pour le chant tragique, poussant à leur «langage-limite» mezzos et barytons, afin d'explorer les zones obscures du déchainement passionnel. Vendetta d'un héros contre l'oppression collective, 
revanche d'une offense personnelle ou justice rendue à un ancêtre bafoué, elle porte une charge spectaculaire particulièrement adéquate à l'opéra par l'exaltation des traumatismes originels.

4 Claudie HUSSON, considérant la vengeance comme une action, mais aussi une représentation dans l'esprit, la pense adaptée comme instrument d'anticipation narrative; elle regarde donc Ce qu'il advient de la vengeance dans "La Chartreuse de Parme“" (pp.139-154). Puisque Michel Crouzet voyait la trame du roman menée par les «vengeances secondaires» d'Ascagne contre son frère, de la Sanseverina contre le prince de Parme, elle remarque que Fabrice l'identifie comme une figure de la vie, dans ses intermittences mêmes, assurant phases d'action, d'oubli, de rêverie, de rebond promesse d'imprévu tel le flux de la destinée.

5 Françoise AUDoueineIX, examinant deux tableaux conservés au musée des Beaux-Arts de Reims, discerne comment Delacroix et Chassériau illustrent Shakespeare (pp. 205-215). Les deux peintres ont marqué un grand intérêt pour son théâtre, depuis la venue des comédiens anglais en 1822, après un voyage en Angleterre pour Delacroix en 1825, lors de la deuxième tournée anglaise de 1827. Qu'il s'agisse de Hamlet devant le corps de Polonius (1854-1856) du premier ou du Spectre de Banquo (1854) du second, inspiré de Macbeth, l'importance donnée au décor, à l'éclairage, au costume signe l'influence de la représentation théâtrale pour rendre l'effroi devant le mal et la culpabilité qu'il engendre.

Les autres articles du volume, organisés selon la technique du «coup de sonde» dans les divers siècles et genres (poésie épique, théâtre et opéra, roman, conte et nouvelle, cinéma et peinture), permettent d'appréhender comment la typologie et les scénarios de la vengeance assurent la fécondité poétique et l'efficacité expressive de ce motif. 